\title{
Experimental and Theoretical Study of Pavements in the Base and Sub-Base Course in Single-Layer and Multi-Layer
}

\author{
Jawad Maher $^{\# 1}$, Saeed Ebrahimi ${ }^{\# 2}$ \\ ${ }^{\text {\# } F a c u l t y ~ o f ~ C i v i l ~ E n g i n e e r i n g, ~ C o n s t r u c t i o n ~ M a n a g e m e n t, ~}$ \\ Islamic Azad University, Bafgh Branch, Bafgh, Iran \\ ${ }^{1}$ Corresponding author email: maher_javad@yahoo.com \\ ${ }^{2}$ Sa_ebrahimi60@yahoo.com
}

\begin{abstract}
Today, the road transport industry is one of the most important industries in which public and private vehicles use it. Usually, most of the development budgets belong to the roads, or in every construction work of the roads is of great importance. Huge traffic load Extreme changes in temperature and accidents create cracks and defects in road pavement structures and reduce safety and increase fuel consumption. Therefore, the Experimental and theoretical study of pavements in the base and sub-base course in single-layer and multi-layer is necessary. How much they make these ways and how much they cost is much to be discussed. In this study, some studies and road pavement stages are presented, and the theoretical methods of optimizing the effective parameters in the base and sub-base course are presented.
\end{abstract}

Keyword - Asphalt ConcreteTransportation Industry, Optimization, Pavement

\section{INTRODUCTION}

Today, the road transport industry is of great importance for the use and safety of public and private vehicles. Using non-standard roads will increase fuel consumption and reduce safety, so much of the development budget will be devoted to ways and standardization. The road pavement consists of several layers, which include asphalt concrete structures which is placed on the last dense layer of the natural soil of existing or modified embankments or floor of the earth and stone slabs. [1]. Asphalt concrete is a mixture of aggregates and abnormalities that are used in combination with other materials. Generally more asphalt production in refineries is the second process that cannot compete with fuels and other products in revenue generation. Two important factors contributing to the structural collapse of the pavement include lower moisture content of the bottom layer carpet and poor core materials. On the other hand, the heavy traffic load daily of severe changes in weather and earthquakes creates cracks and defects in the structure of pavements. Therefore, scientists and engineers are trying to improve the performance of asphalt and paving slabs by modifying or modifying a single pavement asphalt [2]. Fiber and polymers are used to optimize mixes of asphaltic and rock [3]. The most commonly used technique for improving the optimum encryption is by changing the type and concentration of polymers [4].

Choosing a pavement material depends on the quality of the soil. The bearing tolerance level is sensitive and vulnerable to atmospheric agents. Due to the passage of the traffic load where vertical compression stresses are created above the pavement bed, which, if these strains are larger than the permitted value, can lead to a slope in the pavement. According to Table I in general, all soils that are classified in AASHTO from A-1 to A-7 Can be suitable for pavement. Although the soils of the groups of A-4 to A-7 one to the third group of this classification are in adequate condition in dry conditions, it is not suitable in high rainfall areas, saturated and frosty conditions, especially for heavy traffic, and it is better to use this method for the stabilization of materials such as lime Modified and strengthened.

The longitudinal and transverse slopes of the road specified in the roadmap must be provided at the surface of the pavement to pave the layers of the pavement with design thicknesses. Depending on the application of the pavement substrate in the embankment and rocky slopes of the embankment or on the natural surface, structural modifications and optimizations should be made in the pavement area, as presented in Table II. Generally, the pavement systems should have characteristics including continuous grading of frost-free and good drainage properties for rapid water drainage. Here's how to organize the article:

In the second part, some of the theoretical foundations used in this article are discussed. In the third section, the proposed method is considered in this article. In the fourth section, the results are analysed and analysed, and in the fifth part the conclusions will be presented. 
TABLE I. Soil classification

\begin{tabular}{|c|c|c|c|c|c|c|c|c|c|c|c|}
\hline \multirow{4}{*}{$\begin{array}{l}\begin{array}{c}\text { general } \\
\text { classification }\end{array} \\
\begin{array}{l}\text { Main } \\
\text { groups }\end{array} \\
\text { Subgroups } \\
\end{array}$} & \multicolumn{7}{|c|}{ Coarse soil ( Passed from Sieve 200 equals to $35 \%$ or less) } & \multicolumn{4}{|c|}{$\begin{array}{c}\text { Fine-grained soil ( Passed from Sieve } 200 \text { equals } \\
\text { to } 35 \% \text { or less) }\end{array}$} \\
\hline & \multirow{2}{*}{\multicolumn{2}{|c|}{ A-1 }} & \multirow{3}{*}{ A-3 } & \multirow{2}{*}{\multicolumn{4}{|c|}{ A-2 }} & \multirow{3}{*}{ A-4 } & \multirow{3}{*}{ A-5 } & \multirow{3}{*}{ A-6A } & A-7 \\
\hline & & & & & & & & & & & A-7-5* \\
\hline & A-1-a & $\mathrm{A}-1-\mathrm{b}$ & & A-2-4 & A-2-5 & A-2-6 & A-2-7 & & & & A-7-6+ \\
\hline \multicolumn{12}{|l|}{$\begin{array}{l}\text { The } \\
\text { percentage } \\
\text { of Particles } \\
\text { Passed } \\
\text { from Sieve } \\
40\end{array}$} \\
\hline 10 & $\begin{array}{l}\operatorname{maximum} \\
50\end{array}$ & & & & & & & & & & \\
\hline 40 & $\begin{array}{l}\operatorname{maximum} \\
30\end{array}$ & $\begin{array}{l}\operatorname{maximum} \\
50\end{array}$ & $\begin{array}{l}\operatorname{maximum} \\
51\end{array}$ & & & & & & & & \\
\hline 200 & $\begin{array}{l}\operatorname{maximum} \\
15\end{array}$ & $\begin{array}{l}\operatorname{maximum} \\
25\end{array}$ & $\begin{array}{l}\text { maximum } \\
10\end{array}$ & $\begin{array}{l}\operatorname{maximum} \\
35\end{array}$ & $\begin{array}{l}\operatorname{maximum} \\
35\end{array}$ & $\begin{array}{l}\text { maximum } \\
35\end{array}$ & $\begin{array}{l}\operatorname{maximum} \\
35\end{array}$ & $\begin{array}{l}\text { minimum } \\
36\end{array}$ & $\begin{array}{l}\text { minimum } \\
36\end{array}$ & $\begin{array}{l}\text { minimum } \\
36\end{array}$ & $\begin{array}{l}\text { minimum } \\
36\end{array}$ \\
\hline \multicolumn{12}{|l|}{$\begin{array}{l}\text { Dough } \\
\text { Properties } \\
\text { Passed } \\
\text { from Sieve } \\
40\end{array}$} \\
\hline $\begin{array}{l}\text { Fluidity } \\
\text { limit }\end{array}$ & & & & $\begin{array}{l}\text { maximum } \\
40\end{array}$ & $\begin{array}{l}\text { minimum } \\
41\end{array}$ & $\begin{array}{l}\operatorname{maximum} \\
40\end{array}$ & $\begin{array}{l}\text { minimum } \\
41\end{array}$ & $\begin{array}{l}\text { maximum } \\
40\end{array}$ & $\begin{array}{l}\text { minimum } \\
41\end{array}$ & $\begin{array}{l}\operatorname{maximum} \\
40\end{array}$ & $\begin{array}{l}\text { minimum } \\
41\end{array}$ \\
\hline $\begin{array}{l}\text { Dummy } \\
\text { sign }\end{array}$ & $\begin{array}{l}\operatorname{maximum} \\
6\end{array}$ & & N.P. & $\begin{array}{l}\operatorname{maximum} \\
10\end{array}$ & $\begin{array}{l}\operatorname{maximum} \\
10\end{array}$ & $\begin{array}{l}\operatorname{minimum} \\
11\end{array}$ & $\begin{array}{l}\text { minimum } \\
11\end{array}$ & $\begin{array}{l}\operatorname{maximum} \\
10\end{array}$ & $\begin{array}{l}\operatorname{maximum} \\
10\end{array}$ & $\begin{array}{l}\text { minimum } \\
11\end{array}$ & $\begin{array}{l}\text { minimum } \\
11\end{array}$ \\
\hline $\begin{array}{l}\text { group } \\
\text { coefficient }\end{array}$ & \multicolumn{2}{|l|}{0} & 0 & \multicolumn{2}{|l|}{0} & \multicolumn{2}{|c|}{ maximum 40} & $\begin{array}{l}\text { maximum } \\
8 \\
\end{array}$ & $\begin{array}{l}\text { maximum } \\
12\end{array}$ & $\begin{array}{l}\text { maximum } \\
16\end{array}$ & $\begin{array}{l}\text { maximum } \\
20\end{array}$ \\
\hline $\begin{array}{l}\text { Kind of } \\
\text { materials }\end{array}$ & \multicolumn{2}{|c|}{ Rubble and sand } & Fine sand & \multicolumn{4}{|c|}{ Sliced or grained sand } & \multicolumn{2}{|l|}{ silted soil } & \multicolumn{2}{|l|}{ Clay soils } \\
\hline $\begin{array}{l}\text { Grading for } \\
\text { superior } \\
\text { materials }\end{array}$ & \multicolumn{7}{|c|}{ Excellent to good } & \multicolumn{4}{|c|}{ Medium to bad } \\
\hline
\end{tabular}

TABLE II. Classification of structural optimizations on the pavement bed

\begin{tabular}{|c|l|}
\hline Type of pavement bed & \multicolumn{1}{c|}{ Idioms } \\
\hline \multirow{5}{*}{ Dirt cut } & $\begin{array}{l}\text { A) What kind of soil in a thickness of } 30 \mathrm{~cm} \text { under the floor trench with } \\
\text { AASHTO soils (A1 - A7) and or the type of soil designated in the private } \\
\text { technical specifications for the project in question, the modification or } \\
\text { replacement of additives or additives such as lime should be strengthened. }\end{array}$ \\
\hline & $\begin{array}{l}\text { B) The modified materials described in paragraph (A) should be drilled in a } \\
\text { double layer and each layer at a thickness of 15 cm to achieve a specified } \\
\text { percentage density and provide the desired level. }\end{array}$ \\
\hline \multirow{5}{*}{ Stone cut } & $\begin{array}{l}\text { The floor is cut to a maximum of } 15 \mathrm{~cm} \text { below the pavement amount and then } \\
\text { replaced with good quality and acceptable and give the percentage of density to } \\
\text { be characterized. In stone trenches, the type of marl or gypsum should be } \\
\text { replaced at least 30 cm from the cutting floor with two layers of high-quality } \\
\text { materials and each individual layer to be condensed to a certain degree. }\end{array}$ \\
\hline Embankment & $\begin{array}{l}\text { 30 cm of pavement in the embankment should be of suitable soil type in two } \\
\text { separate layers each with a thickness of } 15 \mathrm{~cm} \text { and to be compressed to obtain a } \\
\text { relative density of the characteristic. If the above thickness is not suitable for } \\
\text { proper soils and the required specifications are not provided, then the operation } \\
\text { must be modified outside the specification. }\end{array}$ \\
\hline Existing road surface & $\begin{array}{l}\text { Materials are up to } 30 \mathrm{~cm} \text { deep. If this bed is on par with the asphalt pavement, } \\
\text { then how to prepare the pavement should be mentioned in private technical } \\
\text { specifications. }\end{array}$ \\
\hline
\end{tabular}




\section{RELATIONSHIPS GOVERNING PAVEMENT ANALYSIS}

The study of stress - strain behaviour under various loads is one of the important issues in the design and analysis of pavement layers. In strain - stress behaviour analysis, various parameters such as the Yang modulus (E) obtained from the single-axis test are used. One of the important issues for engineers is the failure of the pavement layers, and, on the other hand, estimating the amount of the sum of the stresses is important. In most cases, the use of the concepts and relationships of the theory of elasticity can partly reflect the behaviour of the soil [5]. In this case, real nonlinear curves should be modelled linearly, so studies with the Young modulus and the interval coefficients also take place.

Important research work has been done in this area since the Second World War in the field of road and rail engineering. Advanced mathematical models based on basic analysis and application of the finite element method in the framework of road construction design. There is also a lot of research in laboratories to determine the mechanics of fatigue structures in materials used on days. The results of the research are standardized in order to be used by road engineers and contractors, as well as for the maintenance and management of roads and roads. Pavement design methods are expressed in three basic structures: rigid structure flexibility structure and semi-rigid structure. For rigid and flexible pavements on a substructure basis and under the rigid base, the twolayer structure and three-layer structures are used respectively. Flexible layers are calculated with the assumption of elastic bedding.

\section{A. ULIDTZ method}

Many attempts were made to correct coefficients by a person named ULIDTZ in 1987 [6], which introduced a relationship that is a function of the thickness of the layers and the Young modulus [7-8]. In the ULIDTZ's method, an issue is analysed by a computer method, and then the same problem is solved by the equivalent thickness method and using the Boussinesq equations. By comparing these answers and the slight difference between them, a correction coefficient (f) should be multiplied by the equivalent thickness. This means, for example, that if we have a two-layer pavement and want to transform it into a modular-layer pavement equal to the substrate modulus, we need to change the thickness of the first layer and convert it to the equivalent thickness (he). Now, if this equivalent thickness is multiplied by the correction coefficient (f), a new thickness is obtained that, if this new pavement is analysed by the Boussinesq method, there are answers that are very close to the actual answers or the answers obtained from the computer programs. We define the correction coefficient (f) for the equivalent thickness value as an equation 1. The amount of this correction factor (f), depends on the thickness of the layers and the ratio of the modulus and the Poisson coefficient as well as the number of layers. The correction coefficient (f) is a coefficient multiplied by the equivalent thickness, but it can be multiplied by the coefficient directly in the result obtained from the option relations.

$$
h_{e}=f \times h_{1} \times\left[\frac{E_{1}}{E_{2}}\right]^{\left(\frac{1}{3}\right)} \mu_{1}=\mu_{2}
$$

\section{B. Lotfi method}

In 1984, Mr. Lotfi et al. [9]presented an empirical relationship that predicts the amount of Mr using finegrained soils. This statistical survey of Mr uses laboratory tests obtained by Barkard in 1982 at the University of Maryland. A total of 13 compounds of different soils were tested in terms of concentration and humidity in different locations. Which results in gaining 64 overall $\mathrm{Mr}$ of $\mathrm{d}$ for all different materials Lotfi's model is as follows:

$$
\log (M r)=1.0016+0.043(C B R)-1.9557(\log (\sigma) / C B R)-175(\log (\sigma))
$$

Where $\mathrm{Mr}$ is Resilient Modulus of Soil Substrates and O is Tension ofLotfi's. For integrating of linear response of Soil substrate Mr, It needs to be solved and at that angle is the angle that depends on the work of the applied wheel on the pavement section.

Considering the common layered pavement in computer solving of program of LCCP-flex-MDOT And taking into account such factors as simplifying resolution time and so on, Matthew and Witczak 1995 had to use an alternative method to simplify it. In this way, user flexibility plays an important role in increasing the design and serviceability scheduling and all kinds of layered materials.

Thus, dams have been proposed by LCCP-flex for pavement analysis. Which later became important due to the low cost of the pavement? The converted cross-section for the pavement system is widely known as a research method for presenting different methods for calculating strain and deformation stress. Boussinesq point-load equations can be easily obtained for use in the substrate of adaptive solutions for the surface charge of any form by numerical integration. 


\section{Westergaard model}

In the Westergaard model [10-11-12]which was introduced in 1984 and used for double-layer pavements with substrate, the flexural stress is fixed below the layer and is calculated along the line to load the load at the edge of the layer as follows:

$$
\sigma_{r}=\frac{3(1+\mu) p}{\pi(3+\mu) h^{2}}\left[\ln \left(\frac{E h^{3}}{100 k a^{4}}\right)+3.84-\frac{4 \mu}{3}\right]
$$

Where ro : is Flexural stress per square millimeter per Newton $\left(\frac{\mathrm{mm}^{2}}{\mathrm{~N}}\right), \sigma$ is Poisson's ratio, Pis Load amount in Newton $(\mathrm{N})$, his Thickness of the layer in millimeters $(\mathrm{mm})$, Eis Young's modulus per square millimeter per Newton $\left(\frac{N}{m^{2}}\right)$, kis Substrate reaction modulus in terms of Newtons per millimeter cubic meter $\left(\frac{N}{\mathrm{~mm}^{3}}\right)$ and ais Wheel contact surface radius in millimeters $(\mathrm{mm})$.

\section{THE PROPOSED FRAMEWORK}

In general, asphalt pavement can be designed in two single-layer, granite-based modes. Asphalt concrete is a single layer of pavement, which is used in sensitive parts of asphalt concrete. This type of pavement is more in line with the construction process and is less than basic operation. Single-layer asphalt concrete works in all traffic-intensive ways. Ground-based pavement uses more than locally available materials and they are used in places where traffic is less. The aggregate base is used in the upper part of the microscope to be compressed.

\section{A. Single layer asphalt concrete}

The main text of this paper is about designing the thickness of single-layer asphalt concrete for pavement that is used as a typical pavement. The following is about the comparison of ordinary asphalt and asphalt. The studies are under the supervision of the Asphalt Institute and other Asphalt Institutes to investigate and compare single-layer asphalt with other asphaltic species. The available studies are both for the laboratory and for the theory. The Asphalt Institute recommends the use of single-layer asphalt concrete. As explained in the previous section, the underlying soil cannot tolerate tensile stresses, so in this case it exhibits weakness in relation to single layer asphalt concrete. In the following, the problem was that the foundation of the earth, while keeping the moisture inside it, would cause damage to the pavement and its substructure. This will reduce the strength of the materials in the road construction, which will further reduce the load bearing capacity of the pavement. Characteristic factors in the design of asphalt concrete tactics are:

1) The traffic conditions in the design basis and other materials in the place

2) Environmental conditions that change the behaviour and service. The different conditions for designing each of these will be described further.

One of the advantages of single-layer asphalt concrete, as already mentioned, is the need for sub surface drainage. Drainage will only be required when underground water levels are high. Or when the water is placed at the bottom of the horizontal arc, the scouring below the surface of the pavement will cause water to accumulate. In these situations, the design of drainage sub-surfaces, which is detailed in the design of drainage drafts, has to be done.

\section{B. Stage construction}

There are several ways to do these days under the way, but the steps should be considered. One way is to find ways to build new settlements. In this case, the asphalt base can be built beforehand so that traffic can be done in the area. The asphalt pavement can be constructed in the next step. In front of those roads, which are greatly increased just after the construction of traffic routes. The greatest advantage of the stage construction is that any construction is done until a stage that has not been poured onto the asphalt can be corrected. This will guarantee a smooth pavement for a long time.

The aggregate used as a base requires an inch of the asphalt layer. That is, the value of the substitution ratio is two. $\frac{7}{2}$ of an inch of unpolluted aggregate that is used as a basis requires an inch of layer of asphaltic. It means that the value of the substitution ratio is $\frac{7}{2}[13]$.

All materials that are to be used in road pavement should be fully tested and the results of the tests show that this issue is both economically and in terms of proper resistance. These experiments yield many results, including the right amount of density and other information. 
Sufficient dirt band should be made for the proposed route and should be identified in the surrounding areas of the soil that can be used. Acceptable capacity for usable soils of any kind should be tested and evaluated. Soil guide from the Asphalt Institute provides information and suggestions on how to use soils. However, in order to avoid potential mistakes, random sampling techniques should be used to assure the location of materials.

Finally, using the drawing of lines to draw up a general project schema, see Fig. 1.

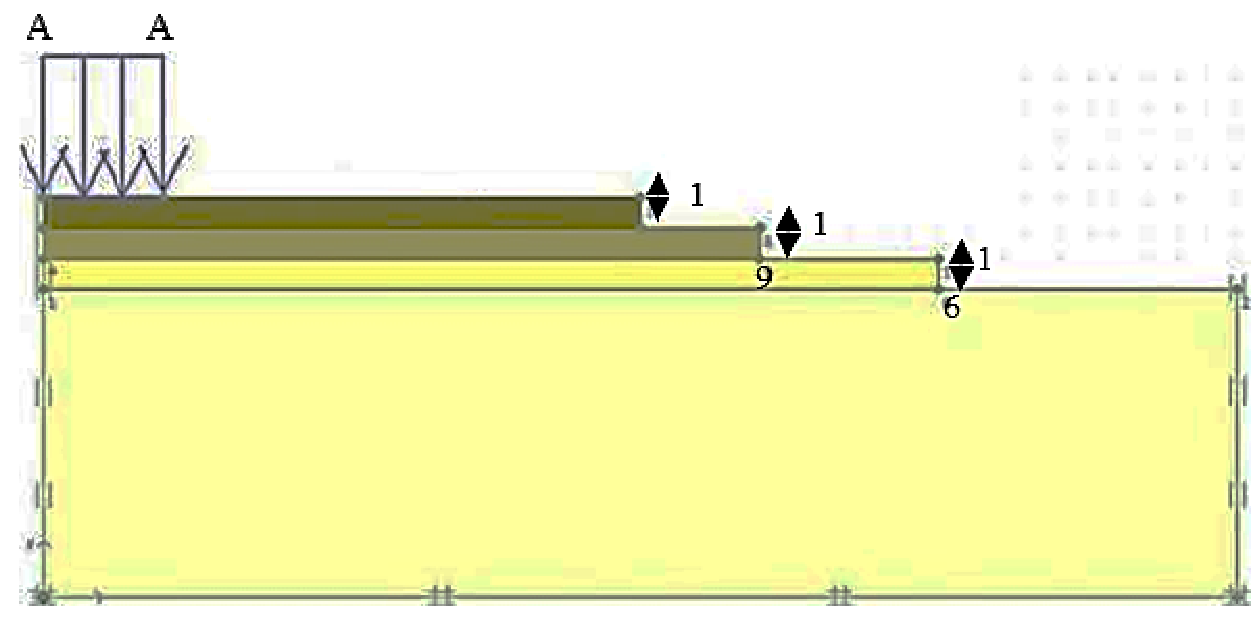

Fig. 1. The overall schema of the model is made

\section{NUMERICAL MODELLING}

The numerical method used in this paper is finite element method. To model geotechnical phenomena using finite element method, there are different software and codes. As previously mentioned, the software used in this research is Plexis software version 6 point 1 . This software has many applications in geotechnical issues, however, it is less used in our country and is used more than two-dimensional Plexis software (Fig. 2).

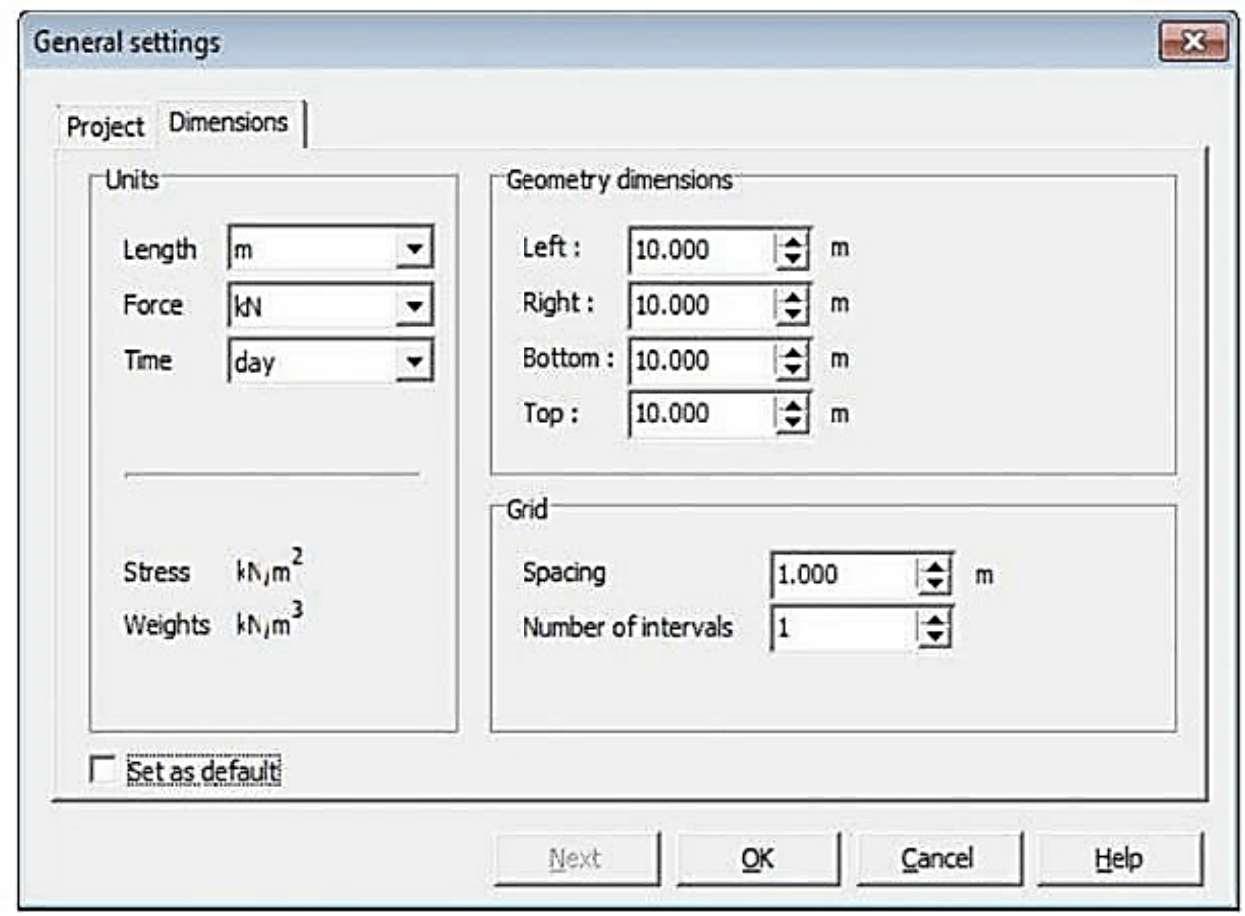

Fig. 2. Define the project scope in the software

In the rules of the Asphalt pavement of Iran, in view of the fact that materials used for pavement in all parts of the foundation and under the foundation and on the profile have been confirmed in this modeling also the information contained in this publication has been used. Information about the input data for the software on soil mechanic information has been removed from Mr. Ameri et al., Which is presented in Table III of Problem 3 (Fig. 3). 
TABLE III. Characteristics of used Modulus

\begin{tabular}{|c|c|c|c|c|c|c|}
\hline Layer & material & $\begin{array}{c}\text { Modulus of } \\
\text { elasticity }\left(\frac{K N}{\mathbf{m}^{2}}\right)\end{array}$ & $\begin{array}{c}\text { Poisson } \\
\text { coefficient }\end{array}$ & $\begin{array}{c}\text { Adhesion } \\
\left(\frac{\boldsymbol{K} N}{\mathbf{m}^{2}}\right)\end{array}$ & $\begin{array}{c}\text { Internal friction } \\
\text { angle } \boldsymbol{\phi}(\text { degree })\end{array}$ & $\boldsymbol{\psi}($ degree $)$ \\
\hline pavement & Asphalt & $1.4 \times 10^{4}$ & 0.35 & 30 & 32 & 2 \\
\hline base & Sand & $7 \times 10^{4}$ & 0.4 & 1 & 32 & 2 \\
\hline sub base & grit & $5 \times 10^{4}$ & 0.35 & 0.1 & 32 & 2 \\
\hline soil & local soil & $4 \times 10^{4}$ & 0.3 & 1 & 32 & 2 \\
\hline
\end{tabular}

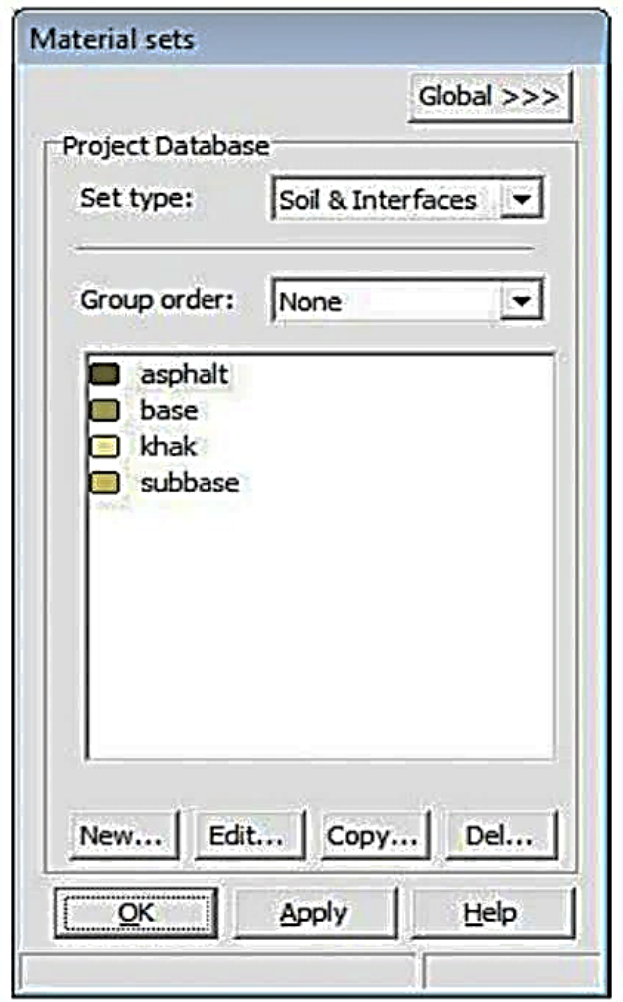

Fig. 3. How to import materials specifications into software

For loading using the asphalt pavement regulations of Iran, a four-axle inter-urban vehicle with a load capacity of 24 is intended to be loaded with 12 wheels of the vehicle to the pavement. Each wheel is assumed to have two tons and is modelled using the software. These loads are commonly used for comparing the asphaltic pavement of single-layer asphalt concrete with conventional asphaltic refurbishment. The width of the load is as large as the width of the wheel of a heavy fatal load of 15 centimetres.

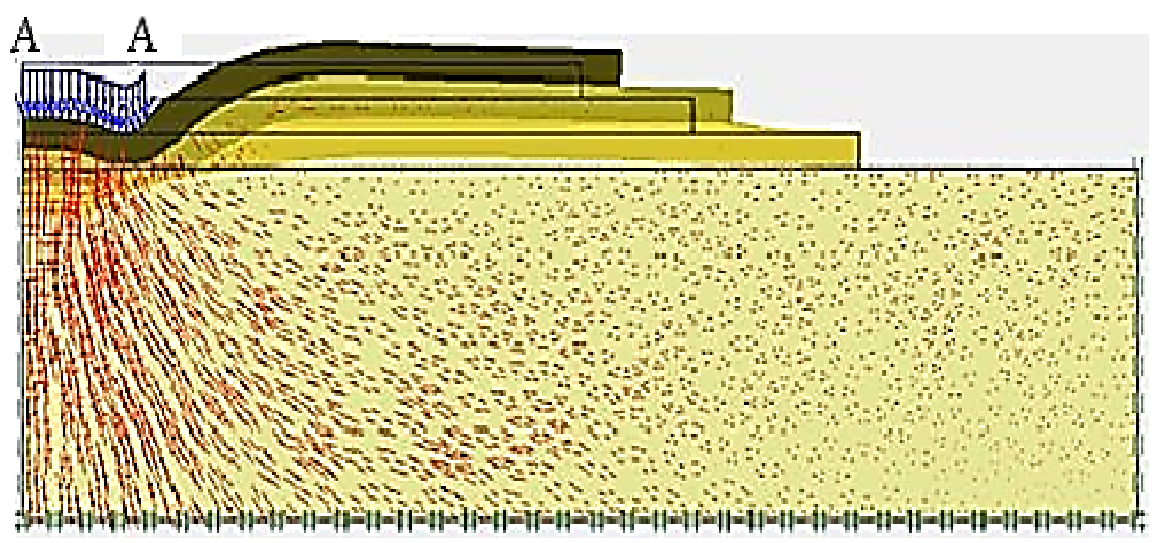

Fig. 4. How to import materials specifications into software 


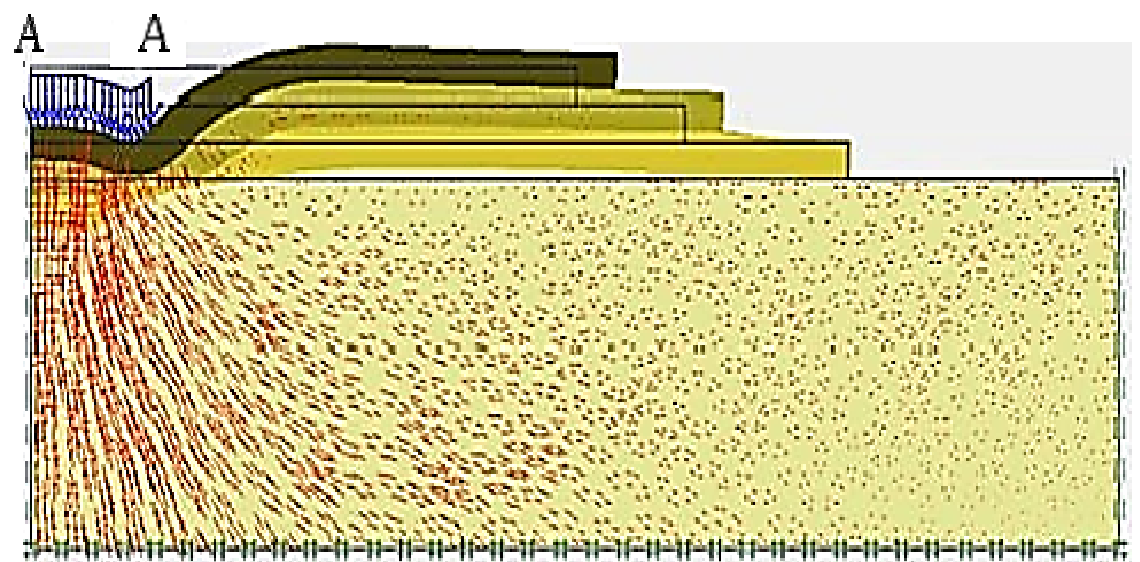

Fig. 5. The result of loading by software in single-layer asphalt

As can be seen in Fig. 4 and 5, the stress in the ordinary pavement is 67 , but in the single layer is 88 , which indicates that the use of single-layer asphalt concrete tensions is reduced to an acceptable level. This means that one-layer asphalt concrete can be less thick and more efficient than ordinary asphalt concrete. This means that one-layer asphalt concrete can be less thick and more efficient than ordinary asphalt concrete. Fig. 6 . Shows the comparison of the results.

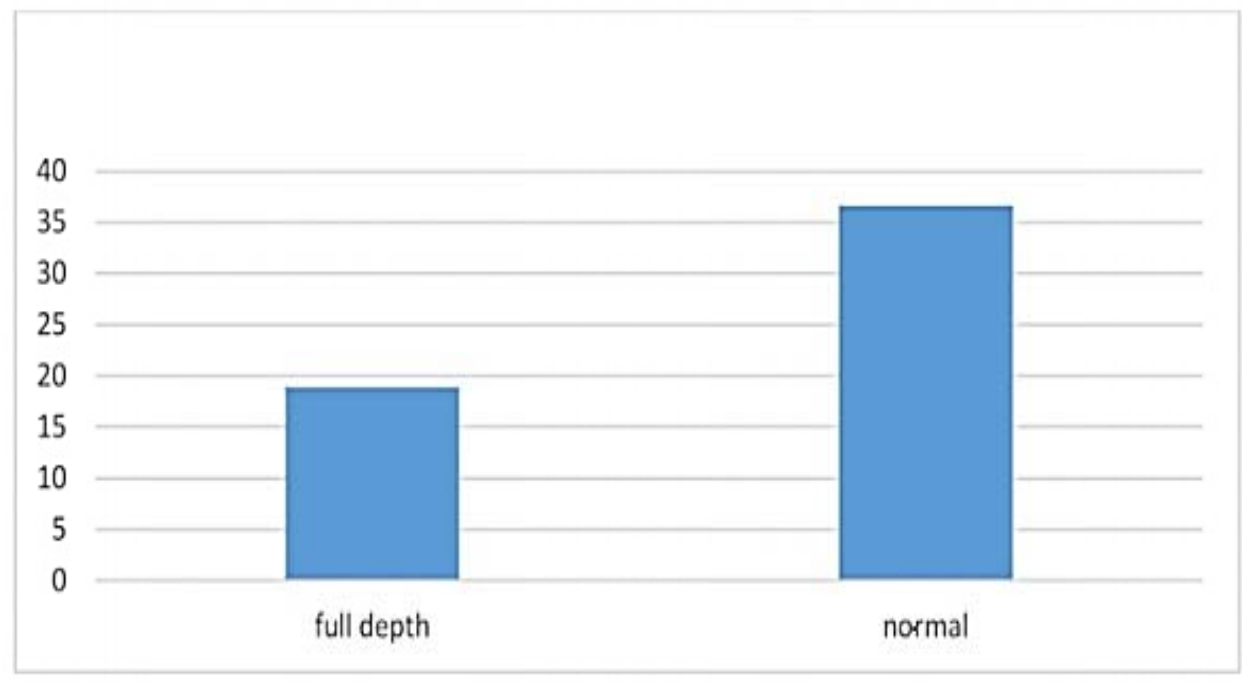

Fig. 6. Comparison of single-layer asphalt concrete tension with ordinary

\section{CONCLUSION}

In this paper, we will come up with a framework to reduce the layers of construction and save time and cost, and given the oil industry in Iran and the production of bitumen asphalted materials in refineries, the implementation of full-depth asphalt pavements will be more economical.

\section{REFERENCES}

[1] K. Terzaghi, R. B. Peck, andG. Mesri. Soil mechanics in engineering practice. John Wiley \& Sons, 1996.

[2] N.F.B.M.Azahar, N.B.A. Hassan, R.P. Jaya,M.A.B.A. Kadir, N.Z.B.M. Yunus, andM.Z.H. Mahmud, "An overview on natural rubber application for asphalt modification," Int J Agric for Plant, vol. 2, p. 212, 2016.

[3] N.I.Yusoff, A.A. Breem, H.N. Alattug,A. Hamim,and J. Ahmad, "The effects of moisture susceptibility and ageing conditions on nano-silica/polymer-modified asphalt mixtures," Construction and Building Materials, vol. 72, pp. 139-147, Dec. 2014.

[4] G. Polacco, S. Filippi, F. Merusi, G. Stastna, "A review of the fundamentals of polymer-modified asphalts: Asphalt/polymer interactions and principles of compatibility,"Advances in Colloid and Interface Science,vol. 224, pp.72-112, Oct. 2015.

[5] W.G. Buttlar, DBozkurt, G.G. Al-Khateeb, A.S. Waldhoff,"Understanding asphalt mastic behavior through micromechanics,"Transportation Research Record,vol. 1681, pp.157-69,1999.

[6] M. Lurdes Antunes, Pavement Design and Materials II Session, FEHRL, 1999.

[7] P. Ullidtz,"Distinct element method for study of failure in cohesive particulate media,"Transportation Research Record: Journal of the Transportation Research Board,vol. 1757, pp.127-33, Jan. 2001

[8] R. Buhari, M. E. Abdullah, and M. M. Rohani,“Predicting Truck Load Variation Using Q-Truck Model,” Applied Mechanics and Materials, vol. 534. pp. 105-110, Trans Tech Publications, 2014.

[9] A. M. Ioannides, Marshall R. Thompson, and Ernest J. Barenberg. "Westergaard solutions reconsidered,"Transportation research record,vol. 1043, pp. 13-23, Jan. 1985. 
[10] P.K. Zysset, X.E. Guo, C.E. Hoffler, K.E. Moore, S.A. Goldstein, "Elastic modulus and hardness of cortical and trabecular bone lamellae measured by nanoindentation in the human femur," Journal of biomechanics, vol. 32, pp. 1005-1012, Oct. 1999.

[11] W. Tu, Response modelling of pavement subjected to dynamic surface loading based on stress-based multi-layered plate theory. Doctoral dissertation, The Ohio State University, 2007.

[12] M. K. Charyulu, and J. B. Sheeler, "Theoretical Stress Distribution in an Elastic Multi-Layered System," Highway Research Record, vol. 228 , pp. 11-17, 1968.

[13] P. Ullidtz, Modelling flexible pavement response and performance, 1998.

[14] P. Ullidtz, "Analytical tools for design of flexible pavements,"Proceedings of the 9th International Conference on Asphalt Pavements, International Society for Asphalt Pavements. 2002.

\section{AUTHOR PROFILE}

Jawad Maher Masters student, Faculty of Civil Engineering, Construction Management, Islamic Azad University, Bafgh Branch, Bafgh, Iran.

Saeed Ebrahimi Ph.D Student,Faculty of Civil Engineering, Construction Management, Islamic Azad University, Bafgh Branch, Bafgh, Iran. 